\title{
Fichte, Reinhold e o problema da apercepção originária kantiana
}

Ivanilde Fracalossi

\section{(2) OpenEdition \\ Journals}

Edição electrónica

URL: http://journals.openedition.org/ref/1154

DOI: 10.4000/ref.1154

ISSN: 2258-014X

Editora

EuroPhilosophie Editions

Refêrencia eletrónica

Ivanilde Fracalossi, « Fichte, Reinhold e o problema da apercepção originária kantiana », Revista de Estud(i)os sobre Fichte [Online], 19 | 2019, posto online no dia 01 dezembro 2019, consultado o 27 outubro 2020. URL : http://journals.openedition.org/ref/1154; DOI : https://doi.org/10.4000/ref.1154

Este documento foi criado de forma automática no dia 27 outubro 2020.

(C) EuroPhilosophie 


\title{
Fichte, Reinhold e o problema da apercepção originária kantiana
}

\author{
Ivanilde Fracalossi
}

\section{NOTA DO AUTOR}

O autor agradece a UFSCar e o apoio financeiro de FAPESP.

\section{0 primeiro princípio na filosofia de Reinhold}

1 Como se sabe, tanto para Fichte quanto para Reinhold, o conceito kantiano de apercepção originária apresenta um grande desafio. Em seu Versuch einer neuen Theorie des menschlichen Vorstellungsvermögens (1789), Reinhold confessa que para ele a compreensão da teoria do princípio da unidade sintética da apercepção foi a mais difícil da $K r V$, tanto que as modificações que tenciona fazer em relação à teoria de Kant partem deste ponto, embora tomem um caminho diferente, uma vez que ele não considera a apercepção transcendental como princípio da dedução da tábua das categorias e juízos, mas a unidade objetiva, da qual a intuição e o entendimento estão sempre já conectados em uma unidade sintética pré-reflexiva ${ }^{1}$. Suas modificações consistem, principalmente, numa escala de várias funções do entendimento, onde a representação se torna o conceito raiz de todas essas funções. Reinhold elabora essa escala para explicar o princípio da unidade originariamente sintética da apercepção, pois considera arbitrário o ponto de vista tomado na $\mathrm{KrV}$ da dedução das categorias, tanto na sua aprioridade como na propriedade para serem formas de conceitos, formas que são a peça principal da analítica transcendental.

O autor da filosofia elementar considera a unidade da apercepção de Kant muito limitada porque seu uso é baseado apenas em intuições, enquanto o uso de um princípio completo exigiria sua base em representações, e a base das faculdades de representações é a consciência, um princípio bem determinado e elucidado 
analiticamente, mas apenas pelo que ele determina sinteticamente, que resulta somente dele mesmo, porque é pressuposto como constituído (als ausgemacht). Ou seja, nos parágrafos II, III e IV das Beiträge, Reinhold mostra como as notas características originais dos conceitos de representação, sujeito e objeto seriam determinadas pela relação dessas partes na consciência. Esses conceitos originários serviriam como fundamento para a representação em geral, porque esta, entendida como o conceito universal de representação, garantiria as notas características comuns à representação sensível, ao conceito e à ideia. Trata-se de um princípio simples, ausente de proposições e de evidência imediata, por isso não requer uma dedução transcendental como a do modelo kantiano, cujas proposições sintéticas fazem o princípio evidente por sua prova, não por ele mesmo. Certamente, este é um motivo importante para a revisão de Reinhold da dedução das categorias de Kant que, no Versuch, sai da consciência do objeto como tal (isto é, do sujeito e da representação representados distintamente) como um fato; e a partir da possibilidade dessa consciência, as naturezas da intuição e do conceito são desenvolvidas (Beiträge I, p. 311).

O programa filosófico, que Reinhold apresenta no Versuch tem um ponto de vista completamente diferente do da $\mathrm{KrV}$ da razão pura. Esta coloca a tarefa modesta de como a metafísica, ou ciência, é possível. o ponto de partida é o fato da experiência, e é por isso que o conceito de metafísica ou ciência desenvolvido na $\mathrm{KrV}$ é, desde o início, adaptado à experiência e, consequentemente, todo conhecimento é conhecimento baseado na experiência como condição de sua possibilidade. No Versuch, por outro lado, trata-se da justificação dos resultados corretos da filosofia crítica a partir de um princípio único e inabalável, razão pela qual este é um programa filosófico mais abrangente que o da KrV. A chamada "proposição da consciência" (Satz des Bewustseins) pretende expressar esse princípio: por um lado, a estrutura mais elementar representa toda a consciência e, por outro, estabelece todas as outras proposições do sistema da razão. Esta proposição deve ser considerada o ponto mais alto da dedução das funções do juízo e das categorias, assim como é a última instância do fundamento para a prova da validade (Gültigkeit) real das proposições consecutivas (Folgesätze).

o fundamento da prova é o fato da consciência [ali ocorre a síntese], de onde emanam a priori todos os componentes formais da representação e, sendo assim, a dedução reinholdiana das categorias se dá unicamente pela determinação das formas do objeto em geral enquanto representado e, por esta razão, ela pode se apoiar exclusivamente na evidência interna da faculdade de representação ${ }^{2}$.

Assim, Reinhold lança mão de um meio original de chegar à faculdade superior de conhecer, ao conhecimento do a priori. Este tem por objeto formas da representação, independentes de toda afecção, logo, só se pode alcançá-lo pela reflexão sobre a forma, a qual retoma, por sua vez, uma nova representação de ordem superior.

\section{As objeções de Schulze ao primeiro princípio reinholdiano ${ }^{3}$}

5 As filosofias de Kant e Reinhold foram duramente criticadas por Schulze com a publicação do Enesidemo, em 1792. Neste texto, Schulze concorda com Reinhold de que só um primeiro princípio absoluto poderia elevar a filosofia ao patamar de ciência rigorosa. Mas contesta que o princípio da consciência possa fornecer um princípio absolutamente primeiro, integralmente determinado por ele mesmo e livre de 
contradição ou de imprecisões. As principais objeções de Schulze são três que, caso corretas, demonstrariam a insustentabilidade da Elementarphilosophie como uma ciência da ciência em geral:

Primeira: o princípio de consciência não é um princípio absolutamente primeiro, sem subordinação e determinação de uma proposição superior, porque, como proposição e como juízo, ele é submetido ao princípio de contradição, última regra de todo juízo. Como averiguar se tudo o que pode ser pensado, se toda ligação do sujeito com o predicado não contém caracteres contraditórios ou, como averiguar a validade do princípio de consciência, como proposição, sem a pré-existência do princípio de contradição? Nas Beiträge $e^{4}$ Reinhold explica que derivar de outras proposições a partir de um princípio significa derivar do princípio a necessidade da ligação das representações que nelas ocorre. Assim, diz Schulze, se a ligação do sujeito e do predicado no princípio da consciência é inegavelmente determinada, o é pelo princípio de contradição e, dessa forma, o princípio de consciência deve estar subordinado a ele.

7 Schulze também não aceita a afirmação de Reinhold contida no Fundamentschrift ${ }^{5}$, texto de 1791, onde o autor diz que "o princípio de consciência seguramente é submisso ao princípio de contradição, mas não como um princípio pelo qual ele seja determinado, e sim unicamente como uma lei da qual não se pode revogar". No mesmo texto (p. 36), Reinhold recorre à autoridade de Crusius $^{6}$ e discorre longamente para mostrar a esterilidade deste princípio, o qual, diz ele, pode fundar apenas verdades lógicas, que dependem apenas do pensamento ou da correção gramatical, uma vez que no juízo, o predicado está ligado ao sujeito, mas esse juízo não recebe nessa ligação uma necessidade e uma verdade reais. Ele também salienta que não se pode saber, pelo princípio de contradição, que algo que acontece tenha uma causa, ou que algo que possa ser considerado uma não-existência deva ter ocorrido. Decorre disso que o princípio de razão suficiente e, portanto, a realidade nos conceitos de causa e efeito, deve ter originariamente em nosso entendimento outro fundamento que não o de princípio de contradição.

8 Mas não convence Schulze, que alega que se não se pode revogar o jugo de uma lei, então esta lei e sua fórmula determinam como um princípio. Além disso, se uma lei, apesar de ser irrevogável não determina, também o princípio de consciência, que exprime a lei do representar, não determina outras proposições, muito menos poderia ser o princípio de todas as proposições filosóficas; seria, no máximo, uma lei à qual essas proposições não poderiam revogar. E por fim, se Reinhold admite nas Beiträge, que o princípio de contradição determina a ligação entre o sujeito e o objeto no princípio de consciência, este não poderia de modo algum ser uma proposição sem essa ligação, logo, ele só pode ser determinado pelo princípio de contradição.

9 Segunda objeção: o princípio de consciência, tal como o expõe a filosofia elementar, não é uma proposição integralmente determinada por ela mesma, pois ela não poderia ser compreendida com exatidão, pela simples reflexão, sobre a significação das palavras que a exprimem, e os caracteres que compõem o fundamento não poderiam estar ligados aos conceitos da proposição, o que impede a univocidade dos caracteres que todos os homens associariam a esse princípio. Isso infringe o enunciado que está na Fundamentallehre $e^{7}$ de que "os conceitos de sujeito, de objeto e de representação estabelecidos pelo princípio de consciência são determinados pela ação de distinguir e de relacionar que esse princípio exprime". Ou seja, o princípio mais alto do conhecimento, um princípio incondicionado, não se determina a si mesmo, porque sua formulação 
requer outros conceitos externos, como os de "relacionar" e "distinguir", que ele mesmo não fundamenta, mas pressupõe. Schulze entende, então, que o princípio da consciência não expõe nada de maneira imediata fora do fato que se produz na consciência, consequentemente, a distinção entre sujeito, objeto e representação não se dá num plano objetivo e real, como quis seu autor, mas subjetivo. Ele também acusa a falta de informação sobre o modo de determinação nessa proposição. Como e de que maneira a representação é diferenciada do sujeito e do objeto?

Terceira objeção: o princípio de consciência não é nem uma proposição universalmente válida, nem uma proposição que exprime um fato independente de toda experiência determinada ou de um certo raciocínio, que acompanharia todas as experiências possíveis e todos os pensamentos dos quais nós tomamos consciência. Além da falta de univocidade da representação da consciência há ainda outros motivos, diz Schulze, que apontam sua ousadia ao pretender o estatuto de uma proposição universalmente válida e garantida. Reinhold diz que em qualquer manifestação da consciência, a representação, o sujeito e o objeto encontram-se como componentes e têm entre eles relações particulares. Só que o autor da filosofia elementar não leva em conta que, em certas manifestações efetivas da consciência, não aparecem todos esses componentes e, por isso, não faz sentido o princípio da consciência afirmar uma proposição universal exprimindo e determinando as características de toda representação e o que há de essencial em todas as manifestações da consciência. Em outras palavras, o que Schulze afirma é que há outros tipos de consciência que não podem ser reduzidos a um relacionamento entre representação, sujeito e objeto.

$\mathrm{Na}$ intuição de um objeto que se supõe existir efetivamente fora de mim, posso discernir bem o meu eu (Ich), que intuiciona, e uma representação que constitui o conteúdo de uma intuição; mas falta nesta intuição, e ao longo dela, a percepção de um objeto diferente do meu eu e da representação que está presente nele ${ }^{8}$.

11 Assim, para Schulze, nada garante que, durante a ação de intuir, a representação seja absolutamente distinta do objeto ao qual ela deve se relacionar. Além disso, ao refletir, mesmo estando consciente do eu pensante e dos conceitos que ele compara, não se é sempre consciente de um objeto particular diferente dos conceitos. Às vezes, há estados da representação e da consciência em nós em que aparecem todos os componentes apresentados pelo princípio de consciência como pertencentes essencialmente a cada um dos estados, mas outras vezes isso não acontece, que é quando a diferença dos componentes não aparece em várias atividades do espírito pelas quais algo é representado.

Ora, conclui Schulze, sendo assim, há um conflito na proposição da consciência, que enuncia: "na consciência a representação é diferenciada do sujeito e do objeto, e relacionada a ambos, pelo sujeito", a qual se declara universalmente válida. Nesse sentido é legítimo perguntar do que se trata então o princípio de consciência se ele não é o que se propusera ser. Schulze arrisca dois palpites: a) o princípio de consciência é uma proposição sintética; b) o princípio de consciência é uma proposição abstrata.

13 É sintética porque o predicado diz do sujeito (consciência) algo que não está já compreendido nele enquanto nota e componente constitutivo9. Desse modo, esta proposição atribuiria, na consciência, algo ao sujeito que não poderia ser encontrado entre suas notas características originárias.

14 Afirma que o princípio da consciência é uma proposição abstrata porque, segundo ele, a esfera e extensão das notas e conceitos que ele estabelece foram determinados por uma 
abstração, portanto, trata-se de notas e conceitos genéricos, pois o que há em comum em certas manifestações da consciência é expresso por esse princípio através de abstração, isto é, ele separa o que elas concordam do que elas divergem.

Schulze tira então a sua severa conclusão: a Filosofia elementar é construída sobre um fato e sobre a análise desse fato, portanto, não pode mais garantir a validade do resultado dos enunciados derivados de sua primeira proposição, já que são baseados nos objetos da experiência e, por meio deles, nunca podemos ter certeza do que foi constatado. E mais: nem um exame profundo e minucioso dos caracteres do fato que funda essa consciência o salvaria, pois não há nele nada que necessitasse de uma retificação importante ou mesmo um remanejamento total em sua estrutura.

\section{Os primeiros passos da Doutrina da ciência}

Fichte concorda com Reinhold de que o primeiro princípio de um sistema de razão deve ser formulado, no que diz respeito à derivação e justificação das consequências, a partir de um certo primeiro princípio ou faculdade suprema, universalmente vigente, e que determine os conceitos de representação e do representável ${ }^{10}$. Também ele afirma que Kant encontrou este conceito com um resultado muito significativo, mas que é preciso aprofundá-lo, já que a apercepção originária nunca foi "estabelecida como um princípio"11, mas expressa apenas como a consciência "condicionante" e não ao mesmo tempo autoconsciência "determinante"12. No entanto, embora os dois autores compartilhem a opinião de que Kant não fundamentara suficientemente a apercepção originária, veem aqui o único acesso correto para a solução do problema do fundamento. "A proposta de melhoria de Fichte fica, por sinal, toda sobre a abordagem de Reinhold, pois está convencido de que o problema fundamental pode ser resolvido no contexto do estabelecimento de um primeiro princípio de filosofia absolutamente certo"13.

17 A Resenha do Enesidemo ${ }^{14}$ traz a primeira tentativa de estabelecer o princípio fundamental da Doutrina da ciência e, neste processo, assimila elementos da filosofia elementar de Reinhold, mas precisa eliminar as suas deficiências mencionadas por Schulze. Na primeira parte de seu livro ele analisa o primeiro princípio da filosofia reinholdiana, onde esboça a conclusão de Schulze, isto é, as objeções que analisamos acima. Diante das observações do Enesidemo, Fichte acredita que o princípio válido para toda a filosofia tem de ser um ainda mais alto que o da representação e do representado expressos na filosofia elementar. Quanto ao princípio de contradição, lembra que Reinhold nega um princípio real, como também Kant, para a filosofia teórica e o reserva apenas para uma validade formal e lógica. Fichte concorda até este ponto, pois não pode ser diferente quando se trata das leis do pensar. Assim, a reflexão sobre o princípio da consciência, enquanto forma, está sob o princípio lógico da não contradição, como o próprio Reinhold confessa "que dele não se pode revogar". Porém, a matéria deste princípio não é determinada por ele, isto é, o princípio de contradição, para Reinhold, é puramente formal e seu princípio supremo é uma proposição analítica.

Como foi visto, o Enesidemo de Schulze, no entanto, nega a validade universal do princípio de consciência porque ele só expressa um fato "ligado a algumas experiências determinadas e a alguns raciocínios". Ele também apresenta diversas manifestações da consciência dadas na experiência, nas quais as ações de distinguir e de relacionar os três componentes exigidos em toda consciência não aparecem, segundo ele. Por isso ele 
nega que este princípio seja determinado por ele mesmo e afirma que a proposição da consciência é sintética e abstrata. No entanto, Fichte, em sua resenha, acredita que este ponto pode ser mais aprofundado do que Schulze o descreveu. Ele diz:

Certamente, se nenhuma consciência é pensável sem esses três elementos [para Reinhold], eles residem no conceito de consciência e a proposição que os expressa é, como proposição de reflexão e como validade lógica, uma proposição analítica. Porém, a ação mesma de representar, o ato da consciência, é evidentemente uma síntese, posto que nela se distingue e se relaciona, e, em particular, a síntese suprema e o fundamento de todas as outras possíveis. Assim, surge aqui a questão tão natural de como é possível reduzir todas as ações do espírito a um compor, de como é pensável uma síntese sem pressupor uma tese e uma antítese ${ }^{15}$.

19 Neste ponto, Fichte aponta uma direção diferente tanto da de Reinhold quanto da de Schulze. A síntese para ele não pode ser um fato, mas um ato ${ }^{16}$. E também não nega a anterioridade lógica na sua fundamentação metafísica, ao contrário, diz que seu recurso de pensamento é inevitável.

Reinhold não aceita a afirmação de Schulze de que sua proposição da consciência seja abstrata, pois seu fundamento não prescinde da sensibilidade, do conceito e da ideia, antes, essas faculdades encontram- se juntas no fundamento de conhecimento. Fichte, por sua vez, analisa esta questão da seguinte forma: se neste princípio se abstrai das condições da intuição, do conceito e da Ideia, então o conceito de mera representação [o qual Reinhold coloca na base de seu fundamento $]^{17}$ não deve se fundar neles, mas os conceitos deles só são possíveis pela distinção e relação de várias representações simples enquanto tais, ou seja, o conceito de representação em geral pode ser determinado sem os de intuição conceito e Ideia, mas estes não o podem sem aquele já estar determinado. E como este princípio está no topo de toda filosofia, pode-se mostrar o contrário, ele não se funda em nenhuma abstração, seja ela determinada ou geral, pois,

se tudo o que se pode descobrir no espírito é um representar e todo representar é inegavelmente uma determinação empírica do espírito, então o próprio representar, com todas as condições puras, é dado à consciência só mediante sua representação, portanto, empiricamente, e toda reflexão sobre a consciência tem por objeto representações empíricas. Sendo assim, o objeto de cada representação empírica se apresenta determinado (no espaço, tempo etc.) ${ }^{18}$.

21 Com esse raciocínio, Fichte conclui, então, que o princípio da consciência reinholdiano, colocado no topo de toda filosofia, funda-se na auto-observação empírica, pois na representação do representar em geral se abstrai necessariamente das determinações empíricas do objeto dado, ou seja, este princípio certamente expressa uma abstração.

Talvez a preocupação de Fichte em dissimular uma possível concordância com o Enesidemo esteja mais voltada a um particular interesse pelo princípio de consciência ${ }^{19}$. Tanto que concorda com Schulze sobre a abstração da primeira proposição reinholdiana, mas não descarta o princípio da consciência como aquele o fez. Ao contrário, sugere uma retificação, pois afirma que o problema desta proposição está apenas em sua base, com o fato. Ele diz no Enesidemo: "evidentemente temos de ter um princípio fundamental meramente formal, porém tal princípio não tem de expressar precisamente um fato (Tatsache), pode expressar também um ação (Tathandlung)". Quer dizer, para Fichte, o problema da filosofia elementar de Reinhold está apenas no pressuposto incorreto, pois, mesmo que negue sua validade universal e o seu caráter analítico, concorda que os conceitos de representação, sujeito e objeto sejam elementos constitutivos da consciência e, com isso, implica necessidade de um princípio a priori, ou 
seja, entende que o princípio de consciência é um princípio que se funda em outro, uma vez que pode ser "rigorosamente demonstrado a priori e independente de toda experiência" ${ }^{20}$. Assim, o problema só de caracteriza quando as notas características da proposição da consciência ocupam o lugar de primeiro princípio. Como retificação, em vez de situar a proposição da consciência como um princípio, Fichte a coloca como o resultado da oposição entre duas teses contrapostas, e propõe um princípio superior que possua por si uma validade real e não só formal, isto é, que determine a forma das representações além de sua matéria e fundamente não só o princípio de consciência, mas também o de não contradição. "Com isso passa de uma lógica transcendental (Kant) a uma metafísica do ser como subjetividade (idealismo)" ${ }^{21}$.

Fichte se manteve no programa de Reinhold de um sistema canônico da razão a partir de um primeiro princípio na perspectiva de uma execução melhorada, eliminando as deficiências mencionadas. De acordo com suas explicações, a principal melhoria deve ser o estabelecimento de um sistema total da razão compreendendo a razão teórica e prática, e saído de um EU ou consciência de si compreendido primeiramente como agente que se põe. Um princípio autossuficiente no qual a forma e o conteúdo se determinem entre si, isto é, precisamente, o que ocorre na posição do eu puro, posto que o conteúdo, a autoidentificação, coincide com a forma, a identidade (eu=eu). Assim posto,

para Fichte, o princípio que reúne todas estas exigências analisadas para ser o primeiro na construção sistemática da filosofia é a Tathandlung do Eu ou Selbstbewusstsein ${ }^{22}$, a atividade absoluta (incondicionada, pura e não empírica), que consiste na mera autoafirmação do eu, em sua autoidentificação. Trata-se de um atuar no qual se esgota a essência da subjetividade, de uma autogênese em que não tem nenhum substrato anterior à própria ação, posto que atuante, resultado e ação coincidem ${ }^{23}$.

\section{Conclusão}

Se considerarmos que Fichte começa com um Eu atuante, que ele descreve uma Doutrina da ciência como sistema completo da razão no contexto do processo de dedução de Kant, verifica-se que ambos pressupõem um $\mathrm{Eu}$, entendido como faculdade e como ato (Aktus), que eles, no entanto, continuam a determinar em diferentes direções e atribuir a ele diferentes funções. Mas ao contrário de Kant, Fichte procura expor uma estrutura peculiar de si ou autoconsciência. A unidade imediata de sujeito e objeto, que Reinhold trouxe à luz em sua definição do conceito de autoconsciência, não deve mais ser atrelado ao conceito fechado de representação, consciência de reflexão e diferença, mas, para sua validade, chegar puro para si $^{24}$. Este objetivo em Fichte segue entre outros com a consideração de que a circularidade kantiana deve ser superada ${ }^{25}$ ou a iteração infinita que surge no pensar reflexivo sobre um $\mathrm{Eu}$ autorreferencial (selbstbezüglich) ${ }^{26}$. Mas, ao mesmo tempo, não se pode e não se deve desistir de determinar estruturalmente essa autoconsciência, que é considerada para si no que diz respeito à sua continuidade no campo da reflexão ${ }^{27}$.

Entretanto, desde os primeiros conceitos estabelecidos na Resenha do Enesidemo sobre a Doutrina da Ciência até as versões mais recentes de novos esboços desta doutrina em 1813 e 1814, encontramos repetidas e renovadas tentativas de Fiche para desdobrar um primeiro princípio de filosofia em um confronto com a apercepção originária de Kant. As diferenças que Fichte opera na interpretação mais precisa e na determinação da 
função do $\mathrm{Eu}$, não o impedem de apresentar uma solução em relação ao problema fundamental da apercepção originária que, de certa forma, assume e continua desenvolvendo um resultado kantiano ${ }^{28}$. Fichte aborda o problema fundamental da apercepção originária no contexto tanto de um pensamento prático-teórico posto, quanto de um pensamento moral-prático postulado, em que considera esses dois pensamentos não como alternativas, mas como dois lados de uma e mesma proposta.

\section{Bibliografia} Felix Meiner Verlag.

40 $\mathrm{KrV})$. Internazionali (MMVI).

BONDELI, M., ((2006) Apperzeption und Erfahrung (Kants Transzendentale Deduktion im Spannungsfeld der frühen Rezeption und Kritik). Basel: Schwabe Verlag.

FICHTE, J, G., (1982) Reseña de Enesidemo. Prólogo, tradução e notas de Virginia Elena López Dominguez e Jacinto Rivera de Rosales. Madri: Libros Hiperión. Reinhold in Jena gelieferten Elentarphilosophie (FSW I, 1-25).

Sämmtliche Werke. Hg. von I. H. Fichte. Berlin 1845/56. 8 Bde: Nachgelessene Werke. Hg. von I. H. Fichte. Bonn 1834/35 (= FSW).

FRANK, M., (1997) Unendliche Annäherung (Die Anfänge der philosophischen Frühromantik). Frankfurt am Main: Suhrkamp Verlag.

HENRICH, D., (1982) Selbstverhältnisse. Stuttgart: Reclam, Ditzigen.

KANT, I., (19980 Kritik der reinen Vernunft, nach der 1 und 2. Orig.-Ausg. Hrsg. von Jens Timmermman. Mit einer Bibliographie von Heiner F. Klemme. Hamburg: Meiner. (=

ONNASH, E, O., (20050 “ Vorüberlegungen zur Herleitung der Urteilsformen und Kategorien in Reinholds Theorie des Vorstellungsvermögens”. In Archivio di Filosofia, LXXIII, n. 1-3. Edited by Marco M. Olivette. Pisa-Roma: Istituti Editoriali e Poligrafici

34 PICHÉ, C., (1995) Kant et ses épigones, le jugement critique en appel. Paris: J. VRIN.

REINHOLD, K, L., (2003) Beiträge zur Berichtigung bisheriger Mißverständnisse der Philosophen. Band I. Hamburg: Felix Meiner Verlag.(= Beiträge I).

(1999) Le príncipe de conscience. Traduction, notes et présentation par JeanFrançois Goubet. Paris: L'Harmattan.

---------- (1978) Über das Fundament des philosophischen Wissens. Hamburg: Felix Meiner Verlag. (= Fundamentschrift).

------------ (2010-2011) Versuch einer neuen Theorie des menschlichen Vorstellungsvermögens. Hamburg: Felix Meiner Verlag, Band I-II (= Versuch).

SCHULZE, G. E., (1996) Aenesidemus oder über die Fundamente der von dem Herrn Professor Reinhold in Jena gelieferten Elementar-Philosophie. Hrsg. von Manfred Frank. Hamburg:

Jéne par Reinhold. Paris: J. VRIN.

Revista de Estud(i)os sobre Fichte, 19 | 2019 


\section{NOTAS}

1. Cf. Onnach, Vorüberlegungen zur Herleitung der Urteilsformen und Kategorien in Reinholds Theorie des Vorstellungsvermögens, p. 99.

2. Piché, Kant e seus Epígones, le jugement critique en appel, p. 100.

3. As objeções estão contidas em Aenesidemus oder Über die Fundamente der von dem Herrn Professor Reinhold in Jena gelieferten Elementarphilosophie. Obra publicada anonimamente em 1792 e composta por uma troca de cartas entre o jovem Hermias, um entusiasta da filosofia de Kant e das contribuições de Reinhold, e por Enesidemo, um cético convencido da inconsistência da filosofia kantiana. E essa obra tinha como meta a exposição daquilo que seriam "resquícios dogmáticos ainda presentes na filosofia kantiana". A influência da tradição pirrônica não se evidencia somente no título de sua obra - que viria a ser também seu pseudônimo. Sua proposta busca indicar a inconsistência dogmática do kantismo sem com isso propor um novo sistema, e alega que a filosofia transcendental se mostrou incapaz de superar o ceticismo humano. Sua tese central afirma que o criticismo falha em sua tentativa de legitimar juízos sobre as coisas em si e de demarcar os limites de nosso conhecimento.

4. Beiträge I, p. 115.

5. Über das Fundament des philosophischen Wissens, p. 85.

6. Christian August Crusius (1715-1775), nasceu em Leune (Saxônia). Estudou teologia, filosofia e foi professor em Leipzig.

7. In Beiträge I, p. 354.

8. Schulze, Énésidème, p. 89.

9. Idem, p. 90, nota 29.

10. Fichte, Reseña de Enesidemo, p. 88, nota 15.

11. Grundlage der gesamten Wissenschaftslehre, Fichte Werke I, p. 99.

12. Zweite Einleitung in die Wissenschaftslehre, FSW, p. 477.

13. Bondeli, Aperzeption und Erfahrung, p.137.

14. Fichte, Reseña de Enesidemo. Madri: Libros Hiperión, 1982. Fichte publica a Resenha ao Enesidemo na prestigiada Allgemeine Literatur Zeitung, através de um convite desta.

15. Fichte, Reseña del Enesidemo, p. 64. (I, 7)

16. Na nota desta mesma página (64) encontra-se uma rápida exposição dos três princípios fundamentais do pensamento de Fichte. Para se chegar à relação recíproca entre o Eu e o não-Eu divisíveis (síntese) são necessárias a autoposição do Eu absoluto (tese) e sua negação (antítese).

17. Acréscimo nosso.

18. Idem, p. 65 (I, 8).

19. Goubet diz que é possível dizer que o fichteanismo é uma crítica da representação (há uma tese de doutorado defendida na Sourbone em 1995 sobre este ponto "Fichte et la Critique de la Représentation" (Cf. Goubet, introdução do Le principe de conscience, p. 11 , nota 27 ).

20. Idem.

21. Introdução à Reseña de Énésidème de Vírginia Elena López Domingues, p. 20. 
22. Rezension des Aenesidemus, FSW I, p. 8.

23. Introdução à Reseña de Énésidème de Vírginia Elena López Domingues, p. 20.

24. Frank, M. - Unedliche Annäherung, pp. 286s.

25. Superar a circularidade kantiana foi a meta também de Reinhold com a escala de espontaneidade que elaborou. Pelo que mostra o texto, Fichte não a considerou executada por Reinhold.

26. Cf. Henrich, D. - "Fichtes Ich", in Selbstverhältnisse, pp. 57-82.

27. Cf. Bondeli, M. - Apperzeption und Erfahrung, pp. 139-140.

28. Idem.

\section{RESUMOS}

In agreement with Reinhold, Fichte supposes that the first principle of a system of reason must be formulated with respect to the derivation and justification of consequences from a certain first principle or supreme faculty. From the earliest established concepts of the WL (1794) to the later versions of new drafts of this doctrine in 1813 and 1814, we find renewed attempts by the author to unfold a first principle of philosophy in confrontation with Kant's original apperception. It is repeatedly stated that Kant obtained a very significant result from this concept, however it must be deepened because the original apperception was never "established as a principle" (Grudlage, FSW 1, 99), and was expressed only as "conditioning" consciousness and not as "determining" self-consciousness (WL, Zwei Einleitung, FSW 1, 477). When Fichte assumes with Reinhold the proposal of a first principle of philosophy valid for both theoretical and practical reasons, he understands the philosophical unification of the original apperception and he claims that Kant, by merely insinuating, gave insufficient grounds for it. It is in this problematic and in the way pointed by the two thinkers to the rectification of the Kantian theory that this article is directed.

ÍNDICE

Keywords: Fichte, Reinhold, Kant, Schulze, original apperception

\section{AUTOR}

IVANILDE FRACALOSSI

UFSCar/FAPESP 